\title{
Facial Dog Bite Injury
}

\section{Srivalli Natarajan, Jyotsna S Galinde, Usha Asnani, Sunil Sidana, Radhika Ramaswami}

\begin{abstract}
The exposed position compounded by the short stature of children makes the face very vulnerable to dog bite injuries. Unlike wounds inflicted by assaults and accidents, animal bite wounds are distinctive as they are puncture type deep wounds which are injected by the bite force, with an inoculum of pathogenic bacteria from the saliva of the attacking dog. Hence, these wounds are at high-risk of infection which is further aggravated by the presence of crushed devitalized tissue, an outcome of the bite force. The key points in successful management of facial dog bites, are thorough cleansing of the wound, meticulous but not overzealous debridement, primary closure, appropriate antibiotic therapy and tetanus and rabies immunization where indicated. A case of a 8-year-old child who had succumbed to multiple facial bite injuries is presented. She was managed by a primary one stage closure with good esthetic and functional outcome.
\end{abstract}

Keywords: Facial dog bite, Animal bite injuries.

How to cite this article: Natarajan S, Galinde JS, Asnani U, Sidana S, Ramaswami R. Facial Dog Bite Injury. J Contemp Dent 2012;2(2):34-38.

\section{Source of support: Nil}

Conflict of interest: None declared

\section{INTRODUCTION}

Bite wounds are always considered as complex injuries contaminated with unique polymicrobial inoculum. As per Dire, $1 \%$ of all emergency injuries are due to human and animal bites. In decreasing order of frequency, locations involved are cervicofacial (36\%), lower extremity (31\%), upper extremity (19\%) and chest (14\%). ${ }^{1}$

Interestingly $78 \%$ of dog bite injuries in children occur in the head and neck while only $10 \%$ affect this region in the adults. ${ }^{2}$ This significant difference is attributable to the short stature of children which makes the face more vulnerable. The lips, nose and cheek comprise the central 'target area'.

Force delivered by a dogs jaw can be as high as $450 \mathrm{lbs} / \mathrm{sq}$ inch. Such high quantum of force delivered by the sharp teeth of these mammals can result in three main types of soft tissue wounds-punctures, lacerations and avulsions with or without actual tissue defect. A typical dog bite results in a combination of puncture-type wound with adjacent tearing of tissue-'hole and tear' effect. Some degree of crush injury also occurs due to the dynamics of the bite. The clinical implications are that puncture wounds are at higher risk of infection, as they harbor microorganisms deep within the wound which has a narrow entry point, and hence poor drainage and has an environment ideal for proliferation of anaerobic bacteria. Crush injuries on the other hand precipitate infection with lower bacterial counts because of resultant tissue ischemia. ${ }^{3}$

The most common aerobic bacteria isolated from infected dog bites are alpha and beta hemolytic Streptococcus (24-46\%), Staphylococcus aureus and Staphylococcus epidermidis (10-25\%), Pasteurella multocida (0-50\%), E. coli, Pseudomonas and Moraxella species. Anaerobic isolates include Bacteroides, Prevotella and Fusobacterium species (13-76\%). More than 50\% of infected dog bites grow anaerobic organisms. ${ }^{4}$

Facial dog bite wounds pose a challenge from the point of esthetics, infection, and at times concomitant grave injuries to the vital structures like airway, cervical spine, vascular structures, intracranial and ocular structures, facial nerve and parotid duct.

A case of facial injury by dog bite is reported which was successfully treated by one stage primary closure.

\section{CASE REPORT}

An 8-year-old female child was brought to our unit with a history of being attacked and bitten by a stray dog while she was playing alone outside her house. Due to the long distance of travel she reported to the hospital about 6 hours after the accident. History revealed that the dog had attacked her without any provocation and that the mammal died a few hours after the accident. On general examination, she was found to be conscious, alert and cardiovascularly stable. Body temperature was normal and vitals were stable. She had suffered multiple wounds which ranged from scratches to puncture wounds on the extremities and back.

On the face, the patient had suffered bilateral circumoral bite injury (Fig. 1). The wound on the left side was a partial thickness avulsive wounds extending from but not involving the corner of the mouth (Fig. 2). There was some particulate debris at the corner of the mouth. There was no evidence of communication with the oral cavity. On the right side the typical hole and tear effect was seen. There was a partial thickness avulsive wound involving the upper lip and the corner of the mouth. Critical evaluation revealed that the partially amputated upper lip was hinged to the lower lip (Fig. 3). The associated tear extended from the nasolabial crease to about $1 \mathrm{~cm}$ below the oral commissure on the right side. There was no evidence of facial nerve injury on either side and the underlying bones were intact. 


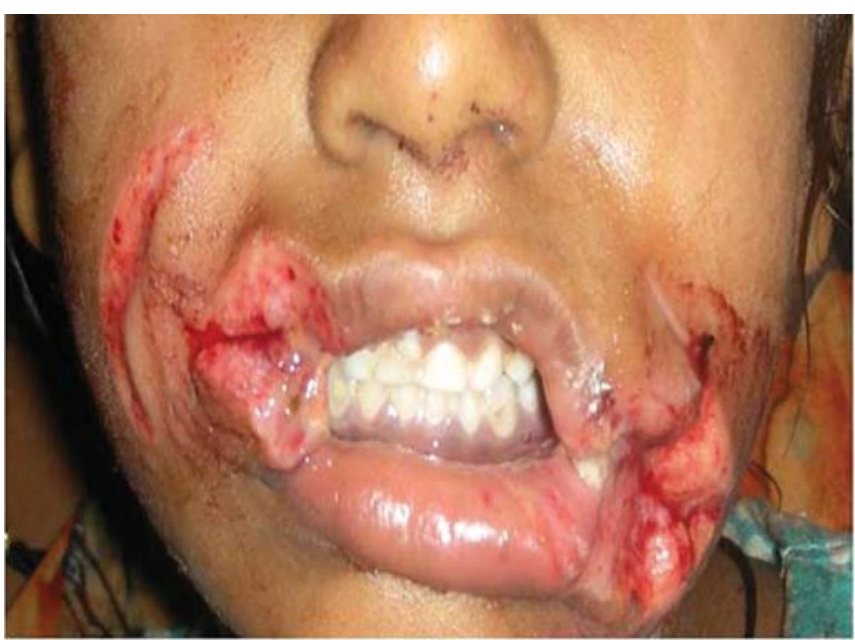

Fig. 1: Preoperative picture showing the bilateral circumoral bite injury

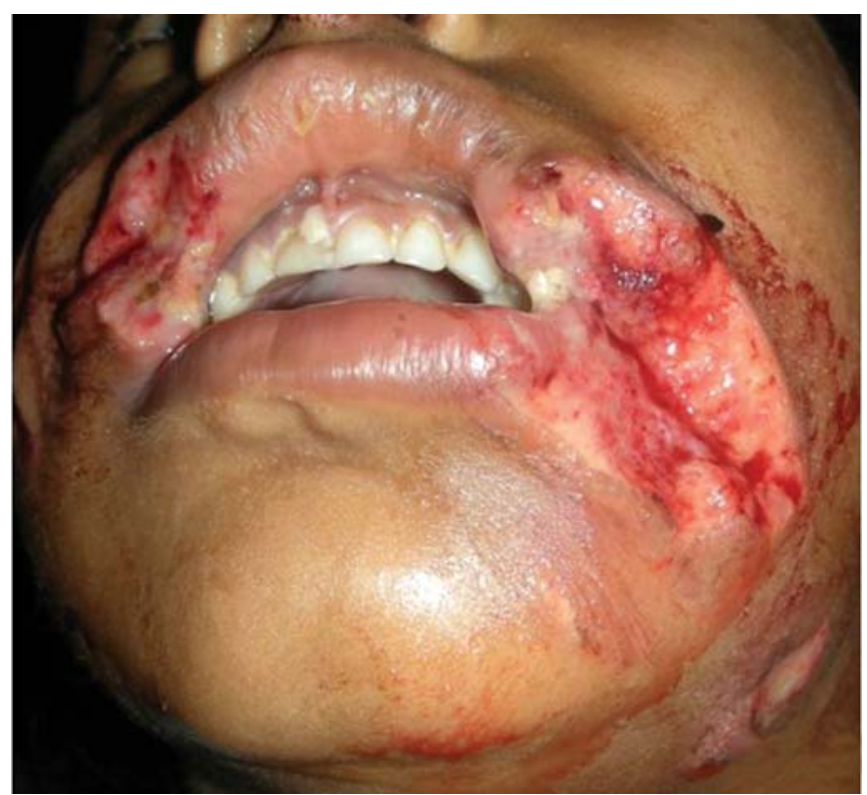

Fig. 2: Preoperative picture showing the partial avulsive wound on the left side

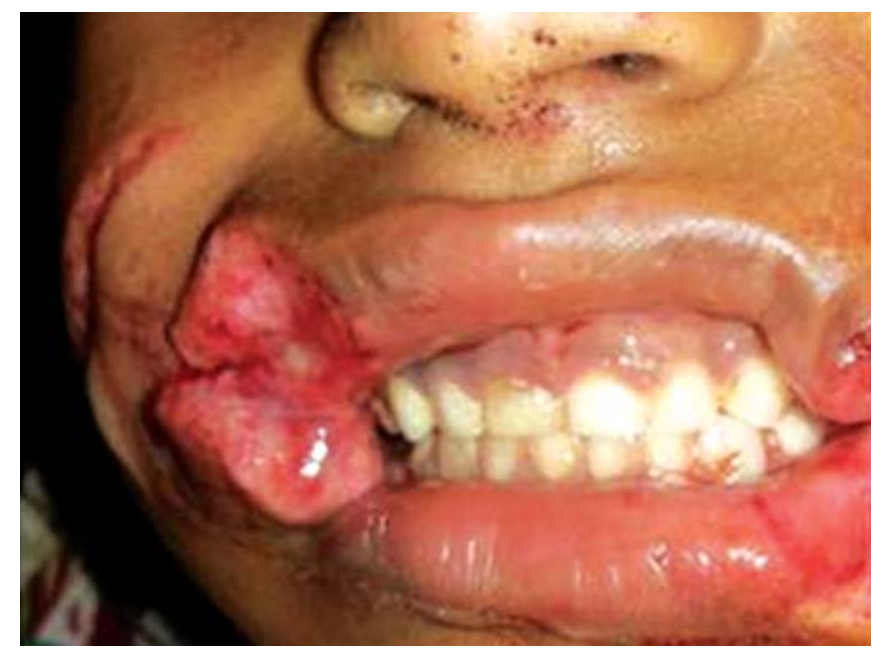

Fig. 3: Preoperative picture showing the partially amputated upper lip hinged to lower lip on right side
Under general anesthesia, all the wounds were thoroughly cleaned and irrigated with normal saline. The facial wounds after cleaning were debrided of particulate matter and devitalized tissue. Conservative trimming of wound margins were done only to remove mutilated tags. Hemostasis was achieved and a meticulous geometric approximation of the wound edges was done. On the left side, a partial release had to be done by extending an incision along the nasolabial crease to mobilize the local flaps and achieve tension free primary closure (Fig. 4). The partially amputated upper lip was returned to its original position and the wound margins were closed with 4-0 ethilon nonresorbable sutures. Subcutaneous sutures were used only at the key points like corner of the mouth, vermillion and where there was dead space. Good repair could be achieved with no distortion (Fig. 5).

Intravenous augmentin $600 \mathrm{mg}$ stat dose followed by augmentin $375 \mathrm{mg}$ twice a day orally for 5 days. Tetanus toxoid was administered. As the dog died within a few hours, it was assumed that it could have been rabid and the child was started on the regime of anti-rabies vaccine. A total of $0.5 \mathrm{ml}$ of the vaccine was given intramuscularly and $0.5 \mathrm{ml}$ injected intralesional. The patient when followed up after a month, and after completion of the course of immunization showed good wound healing without complications.

\section{DISCUSSION}

Dog bite injuries (DBI) particularly in children are a consequence of a combat between a terrified and helpless child and the innate and instinctive aggression of the dog. Injuries can therefore be multicentric and penetrating.

A thorough history and clinical examination should rule out injuries to airway, cervical spine, major vessels,

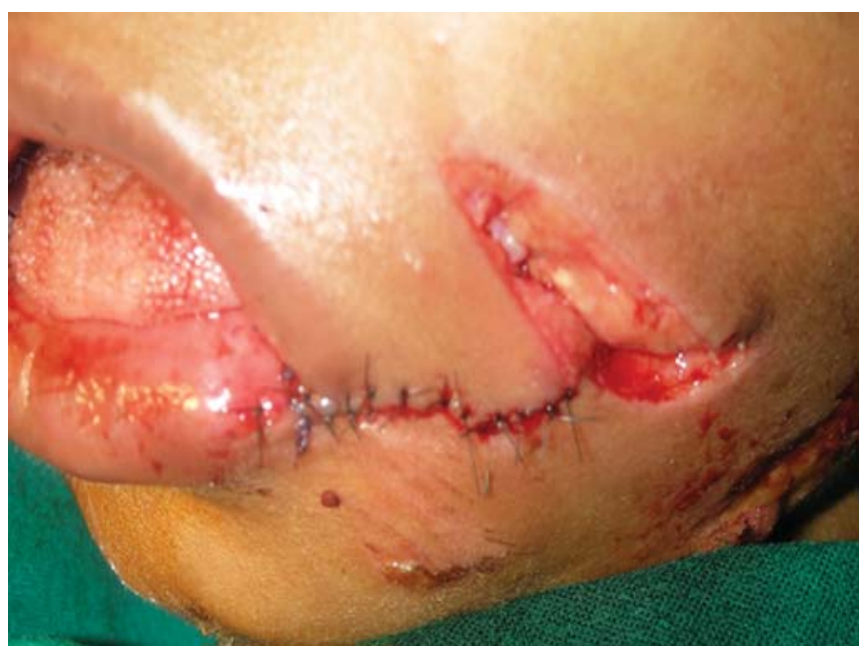

Fig. 4: Intraoperative picture showing local flap mobilization for tension free primary closure 


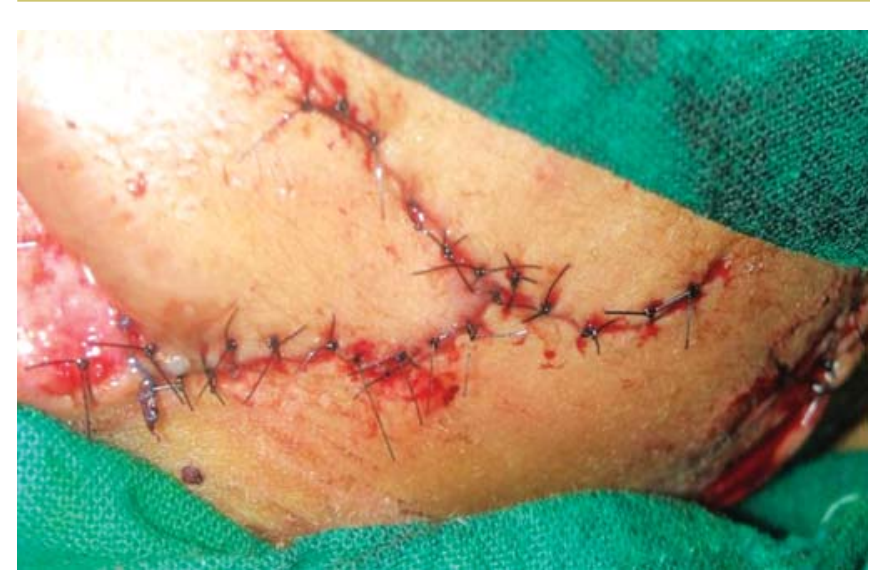

Fig. 5: Postoperative picture showing good repair

intracranial and ocular structures and specialized facial structures like facial nerve, parotid duct and nasolacrimal duct system. Even innocuous injuries to these structures could prove life-threatening and debilitating. The skull bones in children are thin and incompletely mineralized making them susceptible to puncture-type fracture with intracranial injury. ${ }^{5}$ Penetrating neck wounds could present with pulsatile hematoma, profuse external bleeding, subcutaneous emphysema, hemoptysis, difficulty in swallowing or voice changes all of which indicate vascular, laryngeal or esophageal injury. ${ }^{6}$

After initial stabilization the facial wounds need to be assessed for the type, size and depth of the wounds and presence of infection. Lackmanns classification of facial bite wounds based on the extent appears in Table $1 .^{7}$ A major wound infection is defined as fever (over $38^{\circ} \mathrm{C}$ ), lymphangitis, abcess or at least four or five minor criteriaerythema, tenderness, swelling at the wound site, purulent discharge and peripheral leukocytosis of more than $12 \times 10^{9} / \mathrm{L} .{ }^{8}$ The case presented could be classified as type II A on the right side and type III A with some tissue loss on the left side.

History with particular emphasis on the identity of the attacking dog, time of attack, whether the attack was provoked, time elapsed since the time of attack and the tetanus immunization status of the victim is important. Every attempt must be made to capture and quarantine the dog responsible for the attack.
The philosophy regarding management of these injuries has undergone a transformation from allowing the wounds to heal by secondary intention to a more aggressive approach that optimizes esthetic results by primary closure. After several years of debate, there seems to be some consensus on the guidelines for management of facial bite wounds. ${ }^{9}$

The principle steps in management are as follows:

- Proper surgical toilet of the wound by irrigation

- Meticulous but not overzealous debridement of devitalized tissue

- Primary closure of the wound except in high-risk cases

- Appropriate antibiotic therapy

- Tetanus and rabies immunization where required.

Current practice emphasizes that thorough irrigation of such contaminated bite wounds would considerably decrease the bacterial load, remove particulate matter and reduce infection rate. Time honored method of manual irrigation using a 20 to $35 \mathrm{ml}$ syringe equipped with a 18 to $20 \mathrm{G}$ needle is widely recommended. Pulsatile jet lavage at a pressure of 50 to $70 \mathrm{psi}$ is best reserved for grossly soiled wounds in the facial region as they can cause tissue disruption and edema in areas of loose areolar tissue like eyelids and cheek and can cause splash injury to the eyes. ${ }^{9}$ Normal saline remains the preferred irrigant as it does not interfere with the normal wound healing as most antiseptics do. Use of povidone iodine which has an optimal therapeutic balance between bactericidal activity and tissue toxicity should be followed by rinsing with normal saline.

Surgical debridement of devitalized tissue should be kept to a minimum in the facial area as facial tissue due to its rich vascularity can survive on small pedicles. Landmark areas, like the vermillion border, nasolabial fold and eyebrows, should not be inadvertently trimmed.

Because most facial DBIs retain enough skin to allow direct closure, this is the preferred method of treatment and is proven to give best cosmetic results following proper initial management. Subcutaneous sutures are kept to a minimum as they act as foreign bodies and precipitate infection. Avulsive wounds need special management.

\begin{tabular}{|cl} 
& \multicolumn{1}{c}{ Table 1: Classification of facial bite injuries } \\
\hline Type & Clinical findings \\
II A & Superficial injury without muscle involvement \\
II B & Deep injury with muscle involvement \\
III A & Full thickness injury of the cheek or lip with oral mucosal involvement (through and through wound) \\
III B & Deep injury with tissue defect (complete avulsion) \\
IV A & Deep avulsive injury exposing nasal and auricular cartilages \\
IV B & Deep injury with severed facial nerve and/or parotid duct \\
\hline
\end{tabular}


Tissue defects in which primary closure is unobtainable can be managed by local flaps, regional flaps, skin grafts or microvascular reconstruction. As evidenced in our case, DBI involving the face most often can be managed by meticulous geometric reapproximation with minimal mobilization of local tissue.

Unlike in compartment wounds of the extremities, healing by secondary intention is reserved only for highrisk cases in the facial region which include grossly infected wounds, delayed puncture wounds reporting beyond 24 hours with gross edema, avulsive wounds with exposed cartilage as in the ear and wounds in immunocompromised patients.

Antibiotic therapy is almost mandatory in facial polymicrobial dog bite wounds either from a prophylactic or therapeutic point of view. Amoxycillin with clavulanic acid is active against virtually all the bacteria isolated from bite wounds and seem to be the optimal choice. ${ }^{10}$ Amoxycillin with clavulanic acid at a dose of $675+125 \mathrm{mg}$ twice a day by mouth for adults and $25 \mathrm{mg} / \mathrm{kg}$ body weight for children is the treatment of choice. For patients allergic to penicillin, azithromycin is given orally $500 \mathrm{mg}$ on day 1 and $250 \mathrm{mg}$ a day for next 4 days and for children over 6 months, $10 \mathrm{mg} / \mathrm{kg}$ on day 1 followed by $5 \mathrm{mg} / \mathrm{kg}$ for next 4 days. It is recommended that prophylactic antibiotics should be administered for 3 to 5 days and when therapeutic for 7 to 14 days for soft tissue infection. ${ }^{11}$

If the history of tetanus immunization is unclear or fewer than three doses have been given in the past, tetanus immunoglobulin should be administered. Rabies, a dreaded consequence of dog bites due to its $100 \%$ fatality rate, is caused by rhabdoviridae a RNA virus. Once the virus has gained entry it is believed to spread to the central nervous system via peripheral nerves. Incubation period in humans averages 20 to 40 days and is shorter in dogs. Clinical disease is characterized by three stages: Prodromal, encephalitis and brain stem center dysfunction. During the final stages, spasm of the muscles of deglutition cause difficulty in swallowing, which leads to the classic clinical picture of 'foaming at the mouth'. The disease progresses to frank paralysis, coma and death from respiratory distress. Deciding about the need for prophylaxis depends on the history of the circumstances surrounding the attack. When the dog can be captured it is observed for 10 days and if rabies is suspected it is killed and a sample of the brain sent for rabies fluorescent antibody test to demonstrate intracytoplasmic Negri bodies. When capture is not possible, the decision becomes difficult and circumstantial. Factors like whether the attack was provoked and the regional incidence of rabies have to be considered. If rabies prophylaxis is indicated treatment consists of five injections of $1 \mathrm{ml}$ of human diploid cell rabies vaccine given intramuscularly over 1 month (0, 3, 7, 14 and 28 days). ${ }^{12}$ Half the dose can also be given at the wound site.

Inspite of its rich vascularity, facial bite wounds may prove to be a difficult proposition, because of the risk of occult oral communication through the punctured wounds and hence contamination by the patients oral flora. Presence of relatively avascular fat pad in the cheek makes large avulsive wounds more susceptible to infection. A good cosmetic outcome which is of utmost importance in facial wounds demands good local wound care and meticulous repair.

\section{REFERENCES}

1. Dire DJ, Hogan DE, Walker JS. Prophylactic oral antibiotics for low-risk dog bite wounds. Ped Emerg Care 1992;8: 194-97.

2. Harris D, Imperato P, Oken B. Dog bites-an unrecognized epidemic. Bull NY Acad Med 1974;50:981.

3. Panagiotis K, Stefanopoulos. Management of facial bite wounds. Oral Maxillofacial Surg Clin N Am 2009;21:247-57.

4. Jackson P Morgan III, Richard H Haug, Michael T Murphy. Management of facial dog bite injuries. J Oral Maxillofac Surg 1995;53:435-41.

5. Wilberger J, Pang D. Craniocerebral injuries from dog bites. JAMA 1983;249:2685.

6. Schwartz S, Shires G, Spencer F. Principles of surgery (5th ed). New York, NY, McGraw-Hill 1989;232-42.

7. Lackmann GM, Draf W, Isselstein G, et al. Surgical treatment of facial dog bite injuries in children. J Craniomaxillofac Surg 1992;20:81-86.

8. Marco Rainer Kesting, Frank Holzle, Christian Pox, et al. Animal bite injuries to the head: 132 cases. British J Oral Maxillofac Surg 2006;44:235-39.

9. Panagiotis K, Stefanopoulos, Tarantzopoulou AD. Facial bite wounds: Management update. Int J Oral Maxillofac Surg 2005;34:464-72.

10. Goldstein EJ. Current concepts on animal bites: Bacteriology and therapy. Curr Clin Top Infect Dis 1999;19:99-111.

11. Correira K. Managing dog, cat and human bite wounds. JAAPA 2003;16:28-37.

12. Orlando M, Saltman R. Manual of medical therapeutics (25th ed). Boston MA, Little, Brown 1988;446-48.

\section{ABOUT THE AUTHORS}

\section{Srivalli Natarajan}

Professor, Department of Oral and Maxillofacial Surgery, MGM Dental College and Hospital, Navi Mumbai, Maharashtra, India

\section{Jyotsna S Galinde}

Professor and Head, Department of Oral and Maxillofacial Surgery, MGM Dental College and Hospital, Navi Mumbai Maharashtra, India 


\section{Usha Asnani}

Professor, Department of Oral and Maxillofacial Surgery MGM Dental College and Hospital, Navi Mumbai Maharashtra, India

\section{Sunil Sidana}

Reader, Department of Oral and Maxillofacial Surgery, MGM Dental College and Hospital, Navi Mumbai, Maharashtra, India

\section{Radhika Ramaswami}

Postgraduate Student, Department of Oral and Maxillofacial Surgery MGM Dental College and Hospital, Navi Mumbai, Maharashtra, India

\section{CORRESPONDING AUTHOR}

Srivalli Natarajan, Professor, Department of Oral and Maxillofacial Surgery, 504, Tower 1D, Dheeraj Dreams, Bhandup (W) Mumbai-400078, Maharashtra, India, Phone: 09769088803 e-mail: srivallis@hotmail.com 